\title{
Primary cardiac lymphoma and cardiac imaging-A case report of three cases with review of literature
}

\author{
Shivam Dutt ${ }^{1}$, Rohit Tandon ${ }^{1}$, gurpreet wander ${ }^{1}$, Rajiv Gupta ${ }^{1}$, Davinder Singh ${ }^{2}$, and \\ Mandeep Singh ${ }^{1}$ \\ ${ }^{1}$ hero dmc heart institute \\ ${ }^{2}$ dayanand medical college
}

April 27, 2020

\begin{abstract}
Primary cardiac lymphoma is an extranodal non-Hodgkin's lymphoma exclusively located in the heart and/or pericardium, rare in immunocompetent patients, and more frequent in immunocompromised patients. We present 3 cases of primary cardiac lymphoma in immunocompetent patients and review other cases reported in the literature. Two patients were adults and third patient a child. Two patients presented with pericardial tamponade and third case with CHB. Initial diagnosis of tumor was made in all cases by transthoracic echocardiography. Primary cardiac lymphoma arose in right heart chambers in all cases. Histological diagnosis was diffuse $\mathrm{T}$ cell lymphoblastic lymphoma in child and diffuse large B cell lymphoma in adult cases. All three cases received chemotherapy, combined with radiotherapy in one patient. Of our patients, 2 are alive one (child)is asymptomatic ,I adult female died after 3rd chemo cycle and 1 adult male had relapse after 6 months of diagnosis. In conclusion, diagnosis of primary cardiac lymphoma is difficult due to non-specific clinical manifestations and should be considered in patients with a cardiac mass and pericardial effusion. It is confirmed using transthoracic echocardiography and magnetic resonance imaging and certified using cytology or open biopsy. Although prognosis remains poor timely provided chemotherapy may be effective.
\end{abstract}

Title -

Primary cardiac lymphoma and cardiac imaging: A case report of three cases with review of literature

Author-

1. Dr Shivam Dutt (Senior Resident) HDHI unit of DMC institution, Ludhiana, Punjab. Email- shivamdutt007@yahoo.com Postal address - HDHI unit of DMC institution, Tagore Nagar Ludhiana, Punjab.

2. Dr Rohit Tandon (consultant) HDHI unit of DMC institution, Ludhiana, Punjab. E-mail- drrohitt@yahoo.com Postal address - HDHI unit of DMC institution, Tagore Nagar Ludhiana, Punjab.

3. Dr Gurpreet.S.Wander(Prof and HOD)

4. Dr Rajiv Gupta (consultant)

5. Dr Mandeep.S.Sondh(Resident)

6. Dr Davinder singh (consultant - Oncology)

Hosted file Case Report.docx available at https://authorea.com/users/315164/articles/445542-primary-cardiaclymphoma-and-cardiac-imaging-a-case-report-of-three-cases-with-review-of-literature 

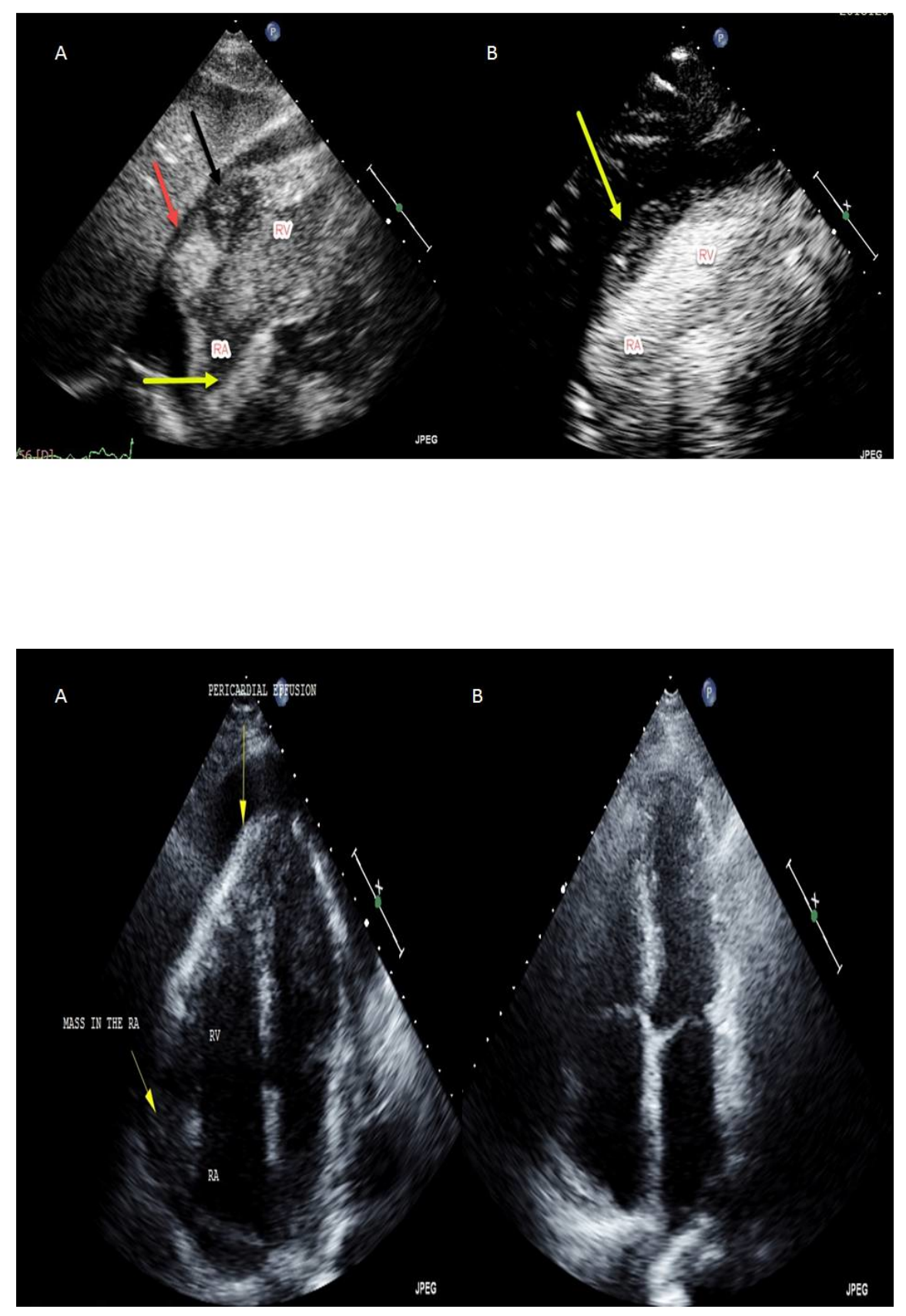

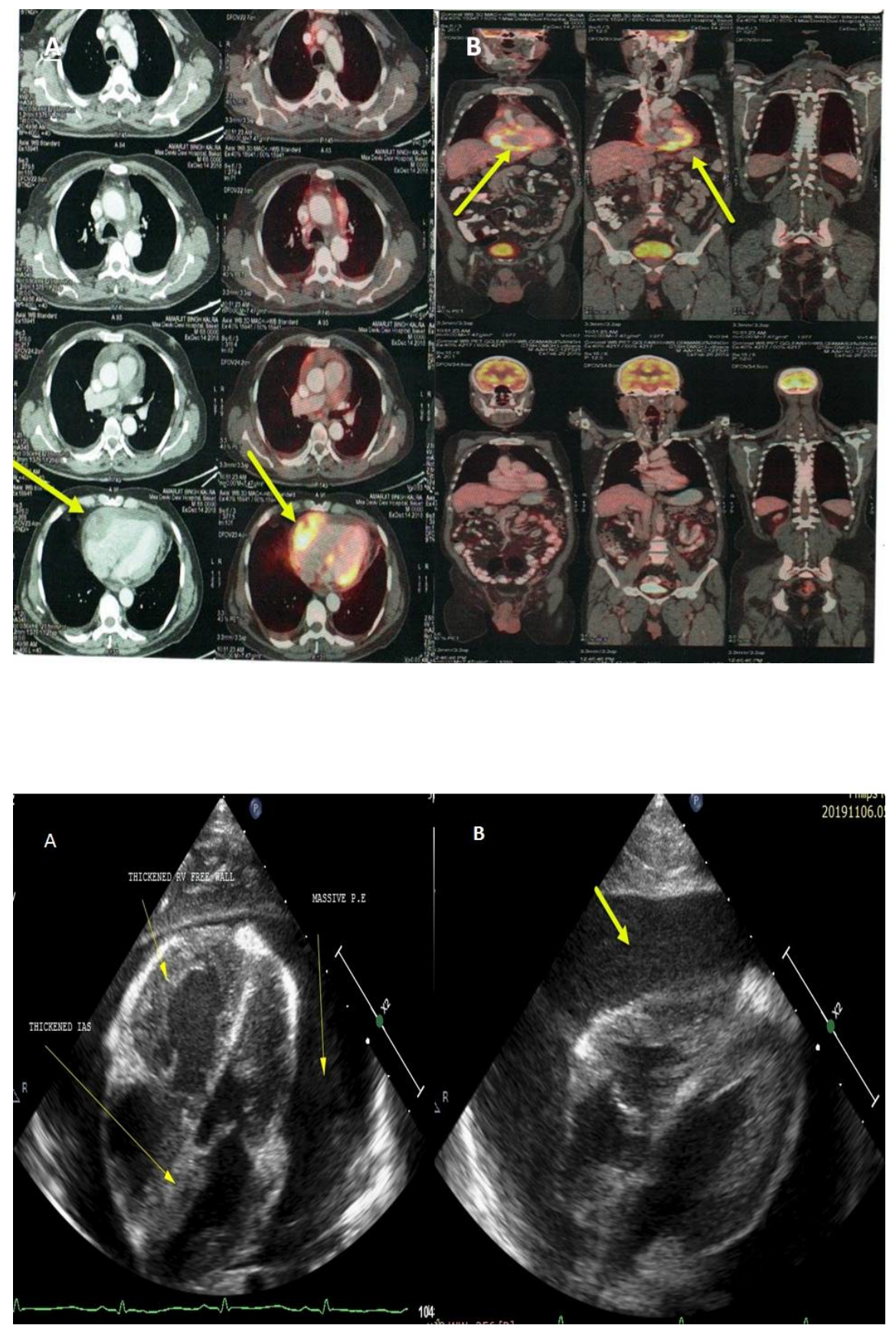


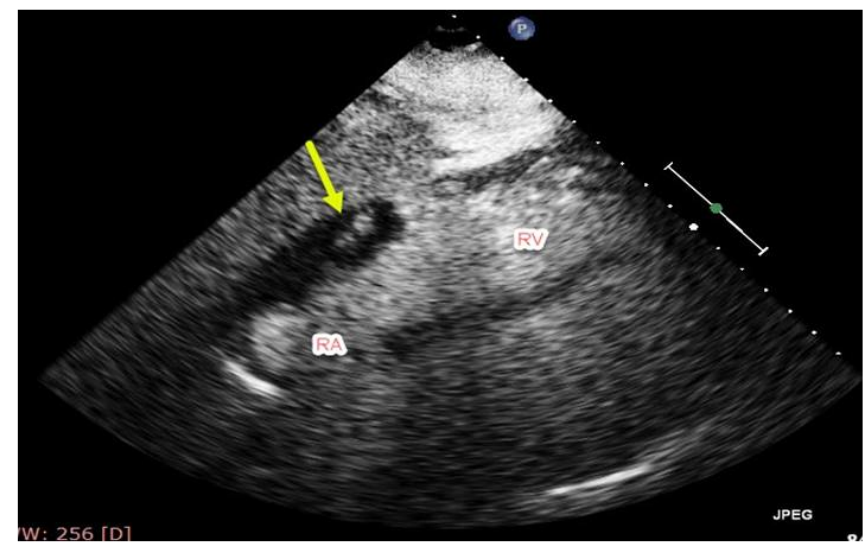

